\title{
Explicit Teaching of Critical Thinking Skills in Communication Science and Disorders
}

\author{
Dana Battaglia \\ Adelphi University, dbattaglia@adelphi.edu \\ DOI: https://doi.org/10.30707/TLCSD4.2/EGYZ9092
}

Follow this and additional works at: https://ir.library.illinoisstate.edu/tlcsd

Part of the Adult and Continuing Education Commons, Curriculum and Instruction Commons, and the Speech and Rhetorical Studies Commons

\section{Recommended Citation}

Battaglia, Dana (2020) "Explicit Teaching of Critical Thinking Skills in Communication Science and Disorders," Teaching and Learning in Communication Sciences \& Disorders: Vol. 4: Iss. 2, Article 6. DOI: https://doi.org/10.30707/TLCSD4.2/EGYZ9092

Available at: https://ir.library.illinoisstate.edu/tlcsd/vol4/iss2/6

This Scholarly Teaching is brought to you for free and open access by ISU ReD: Research and eData. It has been accepted for inclusion in Teaching and Learning in Communication Sciences \& Disorders by an authorized editor of ISU ReD: Research and eData. For more information, please contact ISUReD@ilstu.edu. 


\title{
Explicit Teaching of Critical Thinking Skills in Communication Science and Disorders
}

\begin{abstract}
Critical thinking requires one to be abstract, continually raise questions, independently obtain and reviews evidence, and converge these experiences to offer open-minded solutions. These same traits are required for speech-language pathology students to become successful clinicians. This work describes a mixed method investigation of explicit and infused instruction of critical thinking skills in the context of one graduate-level course in a program accredited from the American Speech-Language Hearing Association. While quantitative findings only demonstrate significant positive change on select items using a Likert scale, qualitative data describe deep learning and growth in the areas of broad life-impact, expansion of knowledge, empathy and perspective taking, and evidence-based practice. Convergence of these data, and future directions are discussed.
\end{abstract}

\section{Keywords}

critical thinking, active learning, pedagogy

\section{Cover Page Footnote}

Acknowledgements The author would like to acknowledge Bernard Gorman, Ph.D., who was instrumental in conducting the statistical analyses for the quantitative portion of this pilot investigation, and Amanda Nagler, who collected and shared data in accordance with IRB protocol and assured student confidentiality. The author would further like the students in Communication Sciences and Disorders, who have served as an inspiration in this work, and are our future in this profession. 
Explicit Teaching of Critical Thinking Skills in Communication Science and Disorders

Paul and Elder (2009) outline an exemplary critical thinker as one who raises vital questions and problems, is able to both obtain and ascertain relevant information, draws well-informed conclusions, offers solutions, and thinks open-mindedly. Similar to the definition of language, there are several schools of thought on defining critical thinking (CT). A commonly held definition, supported by the American Psychological Association, defines CT as purposeful, selfregulatory judgement, resulting in several skills, such as interpretation, analysis, and evaluation and inference (Meltzoff \& Cooper, 2018). Furthermore, CT involves the explanation of evidence, concepts, methods, and context. Individuals who engage in thoughtful CT are inquisitive, and wellinformed (Facione, 1990). Essentially, CT can be considered thinking with intention and application. Additionally, a well-developed critical thinker is one who effectively communicates with others in an effort to reach a solution. Hence, CT is not a construct that can be thought of as a singular skill functioning in a silo. Rather, it is a collection of synergistic skills, complimented by disposition and openness to learning.

It is a historical belief that $\mathrm{CT}$ skills will be acquired naturally by engaging with the higher education learning environment (Finn et al., 2016). Research suggests, to the contrary, that students more readily learn this set of skills when overtly taught or guided (Abrami et al., 2008, 2015). Furthermore, explicit instruction on critical thinking skills in Communication Science and Disorders (CSD) curricula has been identified as necessary and is gaining attention in the literature (Finn et al., 2016), and requires multiple opportunities over time (Grillo et al., 2015).

Ennis (1987) introduced four approaches to explicitly teaching CT stills: general, infusion, immersion, and mixed. These terms are to be used for classifying and describing the myriad of instructional interventions. In the general approach, educators teach CT skills and associated dispositions separately from the content matter. In this case, the topic matter may be speech language pathology, while critical thinking skills may be taught as a separate construct. The infusion approach to teaching CT requires deep, thoughtful, and well-understood subject matter instruction. Using this approach, students are encouraged to think critically within the contentarea subject. Of importance, general principles of CT skills and dispositions are made explicit (e.g., on a syllabus). The immersion approach is one in which students are "immersed" in deep instruction with a content area using CT skills. However, the CT activities are not made explicit as learning objectives in a given course. Finally, the mixed approach consists of a combination of the general approach with either the infusion or immersion approach (Ennis, 1987).

In their meta-analysis, Abrami and colleagues (2008) critically reviewed a total of 117 studies focused on explicitly teaching critical thinking skills. Their findings (while heterogeneous) suggest that there were largely positive changes in critical thinking skills when students are explicitly taught. The mixed method of teaching CT was found to have the most impact on critical thinking skills and dispositions. This was the first literature review to contradict previous findings suggesting that there was little, if any, effect on CT thinking skills based on instructional methods.

An extension of this work was later conducted by Abrami and colleagues (2015), explicitly investigating the efficacy of instructional methods to teach CT skills. Throughout this endeavor, the authors summarized empirical evidence available on CT skills, as well as dispositions data. 
The outcomes of their meta-analysis suggested that both generic and content-specific critical thinking and dispositions can be developed in students. Furthermore, there were a number of effective strategies to do so, such as offering students an opportunity for dialogue as well as presentation of authentic problems. In communication science and disorders, case-studies with active discussion would be an example of merging both strategies.

In the field of speech-language pathology, whereby clinicians are working with individuals with unique and multifaceted communication disorders, training CT approaches to problem solving is crucial. Finn (2011) highlights the importance of thinking dispositions in CT as a cognitive style or attitude toward a belief. Morris et al. (2018) offered suggestions on both assessing and teaching CT skills in CSD coursework. One assessment example included a content centered approach, requiring domain knowledge as a foundation to CT. Similarly, one teaching example included discussing data-based opinions with classmates. They further discussed how teaching these skills require student dispositions and openness to learning, which transcends to clinical practice, and are ultimately interwoven into evidence-based practice.

Pedagogical approaches noted to enhance CT skills in Communication Sciences and Disorders include but are not limited to simulations (Dudding \& Nottingham, 2018; Jansen, 2015; Zraick, 2013), service learning (Mpofu, 2007; Peters, 2011), and problem-based learning (Burda \& Hageman, 2015; Visconti, 2010; Yu et al., 2013) to varying degrees. Simulations offer students an opportunity to critically analyze assessment results to determine a diagnosis (Jansen, 2015). Modalities may include paper-based case studies, standardized patients (Zraick, 2013), virtual clients, and high fidelity mannequins. A national survey of use of simulations in Communication Sciences and Disorders (CSD) graduate level programs revealed that there is an emerging acceptance of use of simulations within course content (Dudding \& Nottingham, 2018). Service learning is defined as a pedagogical strategy integrating community engagement with curricular objectives; this process is deeply reflective and has been explored in CSD (Peters, 2011). Benefits of service learning have been noted to yield increased academic performance, critical thinking skills, and higher student satisfaction (Mpofu, 2007; Peters, 2011).

Finally, problem-based learning (PBL) is a constructivist approach in which an educator provides students with open-ended and complex scenarios to work through in a group setting. These scenarios are designed to mimic those a student is likely to encounter in clinical practice, and can have multiple solutions (Visconti, 2010). In the area of nursing, increasing CT dispositions (i.e., attitudes toward) using problem-based learning (PBL) has been explored in China (Yu et al., 2013). In a comparative study of two cohorts, where one engaged in PBL and the other engaged in lecture based learning, the PBL cohort demonstrated significant positive change in CT dispositions. Subsequently, PBL has been discussed in the context of CSD (Burda \& Hageman, 2015).

In the case of speech-language pathologists working with individuals with autism spectrum disorders (ASD), CT skills are vital for informing clinical practice. As the diagnostic criteria for ASD indicate (American Psychiatric, Association, 2013), ASD is a collection of deficits. A speechlanguage pathologist may be serving 10 individuals with ASD, each of whom is different from the other. Hence, investigation of pedagogy in relation to ASD and speech-language pathology is a relevant to apply explicit training in CT skills.

The objective of this work is to explore how explicitly teaching CT skills can positively affect CT 
skill development in graduate level students in CSD. Gaining an understanding of how critical thinking pedagogy can potentially impact students' abilities to think (and act) critically is the focus of this work. The author is specifically asking the following question: does explicitly teaching critical thinking skills result in self-reports of positive change in critical thinking skills?

\section{Method}

\section{Participants}

This study was approved by the University Internal Review Board (IRB) as exempt status. Three cohorts of data were collected over a year and a half, including data for a total of 56 graduate level students (55 female, 1 male) in CSD, with a mean age of 23 years. While ethnicity data was not collected, the student participants were reflective of the student body, which (at present) is $17 \%$ Hispanic serving. Other minority groups may have also been represented. Data were collected across three traditional (15-week) semesters.

\section{Materials and Procedure}

Data were collected in a required course, entitled, "Autism for the Speech-Language Pathologist." Upon first class meeting, the author (in this case, the instructor as well), introduced a Research Assistant (RA), then left the room for 15 minutes. Confidentiality assurances were offered to students by the RA who was collecting data (while the author was not physically present). The RA described the nature of the study to the students, and explained that there was an option to NOT participate without penalty. The RA reassured students that responses were redacted and enumerated, and the course instructor would not be given any redacted data until after final grades were submitted. The RA again assured that the student experience in the course would not be altered by decision to participate in this study. The RA then distributed and collected surveys, and left the room with them in a sealed envelope. On the final day of class, the RA returned without the instructor present, giving the same survey scale, with the addition of a request to respond to the following question, "How has this class changed your view on critical thinking?" Results were shared with students who requested to review them. The independent variable was the course content and six CT activities offered to students within the context of the course. The dependent variable was change in CT disposition as measured by pre- and post-test.

The RA provided students with 5-point Likert Scale adapted from Sosu (2013) on critical thinking dispositions (see Appendix). Participants were instructed to respond a series of items, formatted from $1-5$, where 1 was "extremely uncharacteristic," and 5 was "extremely characteristic." Upon completion, the instructor returned to the classroom and began instruction with a PowerPoint about critical thinking before introducing new content relevant to ASD and communication.

During six specific intervals during the semester, the instructor engaged the students in evaluative tasks, asking them to reflect on their critical thinking skills/experiences during particular active learning exercises. These six activities were highlighted on the tentative calendar on the course syllabus in advance. Explicit description of each of the six CT activities is outlined in Table 1 below. 
Table 1.

Description of activities students engaged with during class time, with CT objectives (Krathwohl, 2002).

\begin{tabular}{|c|c|c|}
\hline Activity & Description & CT Objective \\
\hline Kanner Analysis & $\begin{array}{l}\text { Review seminal article describing } \\
11 \text { cases on individuals with ASD. } \\
\text { Infer speech, language and } \\
\text { communication characteristics. }\end{array}$ & $\begin{array}{l}\text { Identify common } \\
\text { threads. Distinguish } \\
\text { relevant from } \\
\text { irrelevant information }\end{array}$ \\
\hline $\begin{array}{l}\text { Peer Review of Project } \\
\text { Draft }\end{array}$ & $\begin{array}{l}\text { Exchange drafts, read aloud, and } \\
\text { review papers for technical and } \\
\text { qualitative information. }\end{array}$ & $\begin{array}{l}\text { Evaluate elements of } \\
\text { a logical argument }\end{array}$ \\
\hline Case Study of Theory & $\begin{array}{l}\text { Review case description. Select } \\
\text { theoretical framework to } \\
\text { account for case description. } \\
\text { Draft goals aligned with theory. }\end{array}$ & $\begin{array}{l}\text { Apply knowledge of } \\
\text { framework to an } \\
\text { individual. Identify } \\
\text { discrepancies }\end{array}$ \\
\hline $\begin{array}{l}\text { Autism Diagnostic } \\
\text { Observation Schedule } \\
2^{\text {nd }} \text { edition (ADOS-2) } \\
\text { Demo/Case Study }\end{array}$ & $\begin{array}{l}\text { Review instructor conducing a } \\
\text { diagnostic assessment. List } \\
\text { skills under evaluation. Group } \\
\text { discussion on observation. }\end{array}$ & $\begin{array}{l}\text { Expand knowledge } \\
\text { and differentiate } \\
\text { hidden and overt } \\
\text { assumptions }\end{array}$ \\
\hline Goal Writing Practice & $\begin{array}{l}\text { Review lecture on writing goals. } \\
\text { Watch intervention session and } \\
\text { generate potential goals based on } \\
\text { session observed. Share in group. }\end{array}$ & $\begin{array}{l}\text { Consider all available } \\
\text { information. Raise } \\
\text { questions to seek } \\
\text { additional } \\
\text { information. }\end{array}$ \\
\hline $\begin{array}{l}\text { Case-Based Review of } \\
\text { Behavioral Treatment } \\
\text { Methods }\end{array}$ & $\begin{array}{l}\text { Review and discuss (vague) } \\
\text { individual stories of children with } \\
\text { ASD. Determine which form of } \\
\text { behavioral intervention would be } \\
\text { most efficacious. }\end{array}$ & $\begin{array}{l}\text { Synthesize } \\
\text { information } \\
\text { to determine most } \\
\text { functional approach } \\
\text { to language and } \\
\text { behavior. }\end{array}$ \\
\hline
\end{tabular}

The pedagogical process described here is considered a mixed approach to teaching critical thinking, as there was explicit instruction about critical thinking in isolation during the first class meeting, as well as an infusion approach (i.e., incorporating discussion of critical thinking as it related to content specific material throughout the course) for the duration of the semester. This investigation is a pilot study, conducted as a mixed pre- and post-test research design, including qualitative data (narrative reflections) and quantitative data (pre- and post- survey; Sosu, 2013). 
The qualitative data were obtained by way of student responses to the following question in narrative form, "How has this class changed your view on critical thinking?" Student written responses were read through and transcribed. Using systematic procedures, open coding was used to identify reoccurring ideas and categories of responses throughout the data set. An individual in a related healthcare profession, experienced in qualitative analysis went through the initial coding of responses, independently of the author, for consistency. Categories of information were aggregated, denoting four major themes in changes in critical thinking (e.g., critical thinking impacting all aspects of life, expanding knowledge in critical thinking, invoking empathy and perspective taking, and contributing to evidence-based practice). The total number of appearances of these themes was 35 (see Table 2). Description of each theme is located in the Results section.

Table 2.

Total number of appearances of themes in student responses. Theme Total Appearances in Responses

$\begin{array}{ll}\text { Critical thinking impacting all aspects of life } & 11 \\ \text { Expanding knowledge in critical thinking } & 7 \\ \text { Invoking empathy and perspective taking } & 9 \\ \text { Contributing to evidence-based practice } & 8\end{array}$

\section{Results}

Results of this study are described in two ways. First, quantitative data were collected and compared via pre- and post-test means. Second, qualitative analysis of written responses were conducted. Results of both analyses are shared below.

Quantitative findings. The data were analyzed as a series of two-factor ANOVA with one between subjects factor with three levels (cohorts) and one within-subject factor with two levels (pre-versus post-testing.). Examination of these results indicated there were no significant main effects for cohort, nor were there any significant interaction effects between cohort and pre- posttest results. A supplemental document for specific values can be made available upon request. However, there were a select few significant pre- to post-test differences and these will be presented in a series of paired sample $t$-tests. See Table 3. Examination of this table will show that three items showed significant differences, and their effect sizes were small to moderate.

Collapsing the data across all three cohorts, a 2-factor repeated measures ANOVA was conducted across all 18 test items. One between group factor was cohort (with three levels), and the within subject factor was pre- and post-test scores.

Table 3.

Pretest Post-test data for Disposition Likert Scale.

\begin{tabular}{lllllll}
\multicolumn{8}{c}{ pretest } & post-test \\
\hline Item \# & \multicolumn{1}{c}{ Question } & $M(S D)$ & $M(S D)$ & $t$ & $p$ & Cohen'sd \\
\hline $1 \quad \begin{array}{l}\text { I would prefer simple } \\
\text { To complex problems }\end{array}$ & $2.84(.9)$ & $3.33(.91)$ & -3.98 & $.001^{*}-0.53$
\end{tabular}




\begin{tabular}{|c|c|c|c|c|c|c|}
\hline 2 & $\begin{array}{l}\text { I like to have the responsibility } \\
\text { of handling a situation that } \\
\text { requires a lot of thinking }\end{array}$ & $3.57(.69)$ & $3.61(.86)$ & -0.66 & .395 & -0.09 \\
\hline 3 & Thinking is not my idea of fun & $2.62(1.05)$ & $2.52(.95)$ & 0.81 & .350 & 0.11 \\
\hline 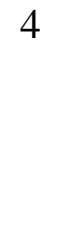 & $\begin{array}{l}\text { I would rather do something } \\
\text { that requires little thought } \\
\text { than something that is sure } \\
\text { to challenge my thinking } \\
\text { abilities }\end{array}$ & $2.39(.86)$ & $2.35(.86)$ & 0.24 & .738 & 0.03 \\
\hline 5 & $\begin{array}{l}\text { I try to anticipate and avoid } \\
\text { situations where there is a } \\
\text { likely chance I will have to } \\
\text { think in depth about } \\
\text { something }\end{array}$ & $2.25(.85)$ & $2.14(.79)$ & 0.80 & .467 & 0.11 \\
\hline 6 & $\begin{array}{l}\text { I find satisfaction in } \\
\text { deliberating hard for long } \\
\text { hours }\end{array}$ & $2.90(.87)$ & $2.88(1.01)$ & 0.25 & .799 & 0.03 \\
\hline 7 & $\begin{array}{l}\text { I only think as hard as I } \\
\text { have to }\end{array}$ & $2.28(1.08)$ & $2.11(.98)$ & 1.02 & .236 & 0.14 \\
\hline 8 & $\begin{array}{l}\text { I prefer to think about small } \\
\text { daily projects to long-term } \\
\text { ones }\end{array}$ & $3.0(1.21)$ & $2.91(1.01)$ & 0.18 & .722 & 0.02 \\
\hline 9 & $\begin{array}{l}\text { I like tasks that require little } \\
\text { thought once I've learned } \\
\text { them }\end{array}$ & $2.98(1.10)$ & $2.81(.99)$ & 1.14 & .178 & 0.15 \\
\hline 10 & $\begin{array}{l}\text { The idea of relying on thought } \\
\text { to make my way to the top } \\
\text { appeals to me }\end{array}$ & $3.67(.91)$ & $3.67(0.79)$ & -0.12 & .808 & 0.02 \\
\hline 11 & $\begin{array}{l}\text { I really enjoy a task that } \\
\text { involves coming up with } \\
\text { new solutions to problems }\end{array}$ & $3.8(0.81)$ & $4.09(0.66)$ & -3.10 & $.004 *$ & -0.41 \\
\hline 12 & $\begin{array}{l}\text { Learning new ways to think } \\
\text { doesn't excite me very much }\end{array}$ & $1.87(0.78)$ & $1.89(0.86)$ & -0.41 & .658 & -0.05 \\
\hline 13 & $\begin{array}{l}\text { I prefer my life to be filled with } \\
\text { puzzles that I must solve }\end{array}$ & $2.92(1.0)$ & $2.93(1.12)$ & -0.35 & $.035^{*}$ & -0.05 \\
\hline 14 & $\begin{array}{l}\text { The notion of thinking } \\
\text { abstractly is appealing to me }\end{array}$ & $3.48(0.81)$ & $3.35(1.06)$ & 0.90 & .357 & 0.12 \\
\hline 15 & $\begin{array}{l}\text { I would prefer a task that is } \\
\text { intellectual, difficult, and } \\
\text { important to one that is } \\
\text { somewhat important but } \\
\text { does not require much thought }\end{array}$ & $3.44(0.89)$ & $3.35(1.04)$ & 0.65 & .473 & 0.09 \\
\hline 16 & $\begin{array}{l}\text { I feel relief rather than } \\
\text { satisfaction after completing a } \\
\text { task that required a lot of mental }\end{array}$ & $3.20(1.0)$ & $3.28(1.13)$ & -0.48 & .738 & -0.06 \\
\hline
\end{tabular}


effort

\begin{tabular}{|c|c|c|c|c|c|c|}
\hline 17 & $\begin{array}{l}\text { It's enough for me that something } \\
\text { gets the job done; I don't care } \\
\text { how or why it works }\end{array}$ & $1.93(0.85)$ & $2.11(0.90)$ & -1.54 & .151 & -0.20 \\
\hline 18 & $\begin{array}{l}\text { I usually end up deliberating about } \\
\text { issues even when they do not } \\
\text { affect me personally }\end{array}$ & $3.61(1.10)$ & $3.53(1.17)$ & 0.39 & .680 & 0.05 \\
\hline
\end{tabular}

Question number, question example, pre-test and post-test Means (M) and Standard Deviations (SD) for all responses to 18 items. ANOVA outcomes based on each of the 18 test items. $t$-value, $p$-value, and Cohen's $d$ are shown with degrees of freedom at 56.

It should be noted that when multiple tests are performed, the chances of making a Type-I error increase as the number of tests increase. In order to protect the familywise error rate at the 0.05 level or less, a Sidak correction for correlated dependent variables was performed using the Bonferroni Correction procedure at the SISA site (http://www.quantitativeskills.com/sisa/calculations/). Given 18 tests, an alpha level .05, and an average correlation among items of 0.27 , the corrected critical p-value should be 0.003 . Therefore, using this very conservative criterion, only Item 1 results would meet this criterion.

Qualitative findings. Four themes emerged as a result of this pilot investigation, as follows: Critical thinking impacting all aspects of life, Expanding knowledge in critical thinking, Invoking empathy and perspective taking, and Contributing to evidence-based practice. Additional details now follow.

Critical thinking impacting all aspects of life. Eleven students reported application of information with a given context, and to have generalized critical thinking approaches beyond the clinical setting. Students reported that they expanded ways to evaluate a situation; they have improved awareness of critical thinking skills in multiple environments and scenarios. Finally, students reported that they have increased value of thinking critically and improved their own thinking processes globally. Excerpts from student reports reflecting change in all aspects of life include:

- "[Author] always made us think about the information given and think about how it could be applied within our field or within life."

- "This class has allowed me to think about situations in different ways."

- "I find it more interesting and helpful to think critically."

- "Critical thinking can be applied to anything."

- "I find myself using critical thinking more because of the questions asked to us in class."

- "[This class] has helped me understand how to approach scenario with a holistic view."

Expanding knowledge in critical thinking. Seven students explicitly self-reported that they have expanded their knowledge in critical thinking skills. Furthermore, they have increased experience in problem solving and decision-making. Finally, students self-reported to have increased understanding of CT and improved the thinking process globally. Excerpts are now shared below.

- "These projects have taught me to expand my knowledge and figure out other ways to analyze or solve a situation." 
- "It made me evolve my thinking beyond what I usually think."

- "It's given me a more definable view on critical thinking, expanded my view, rather than changing it."

- "I am able to provide a more concise definition of critical thinking."

Invoking empathy and perspective taking. Nine students reflected upon the importance of context and family and societal values. They demonstrated value of viewing each client as an individual; they appeared to have understood unique situations and skills required for the most efficacious client based intervention. Finally, students reported to have a heightened sense of empathy, impacting clinical decision making.

- "Sometimes what I think or infer is not enough, but empathizing allows for a more educated inference and decision."

- "This class changed my view on critical thinking because I have seen through her experiences that not every individual is the same."

- "This class has taught me the importance of putting myself in another's shoes, then working toward a solution, decision, or explanation."

Contributing to evidence-based practice. Eight student responses reflected a deeper dive into evidence based practice as a result of critical thinking. Specifically, students reported incorporating research and family perspectives based on evidence. They reported an increased awareness of CT and improved application of different forms of evidence in clinical practice.

- "It's made me more aware of what critical thinking is and how applicable and important it is in the field of Speech Language Pathology."

- "Taught me how to apply research to prove my points/thoughts."

- "It has caused me to look at evidence based practice and what has good scholarly support in comparison to other sources."

- ".... By making me realize the importance of thinking of others cultural believes and well as [factors] unrelated to speech."

\section{Discussion}

Findings for the quantitative data illuminate the challenges of teaching critical thinking skills; across all three cohorts there were no significant changes overall. When viewed item by item, only three items demonstrated significant positive change pre- and post-testing. These three items were, "I would prefer simple to complex problems," "I really enjoy a task that involves coming up with new solutions to problems," and "I prefer my life to be filled with puzzles that I must solve." Interestingly, these three items attest to a desire for active engagement in the learning process. The significant differences reflected a more general approach to CT, rather than disposition toward a specific task.

In an effort to explain the overall findings, it may be the case that that initial self-ratings (pre-tests) were inflated. Two plausible explanations for these inflated self-reports may be (1) social desirability and (2) view of one's own abilities. First, it may be the case that students may not have been completely transparent on the initial surveys due to social desirability. That is, at the risk of being viewed as less than desirable by a rater, participants may not have responded to disposition statements with complete honesty (Edwards, 1957). If this was the case, responses to 
self-ratings on CT were inaccurate from the onset. Second, it may be that students, separate from social desirability, truly believed that their skills were higher than they may have been, due to selfinflated views of their own abilities. Considering that the students have been accepted into a rigorous graduate level program, this may be a plausible, though speculative, explanation. There is also a third possible explanation of findings in pre- and post-test responses. It may be, indeed, there was no change in the CT skills of students from the first class to the final class. However, the fact that there was a significant and positive change in the three questions related to CT and active learning, in addition to qualitative findings offered in Phase 2 of results, does not support this notion.

Findings for the qualitative data were expected, and certainly respond to the research question at hand. The mixed approach to teaching critical thinking, in which there is a combination of explicit instruction about critical thinking as well as critical thinking infused for the duration of the course, seems to have promise for higher education in speech-language pathology. The fact that qualitative and quantitative findings are somewhat dichotomous warrants further reflection and explanation. That is, 15 items in the Likert scale did not show significant differences in CT skills dispositions as a whole. However, in triangulating these data, it is quite notable that student comments about general CT skills mirror the positive change noted on the three items on the Likert scale which did demonstrate significant positive change. Furthermore, student comments about evidence-based practice in the profession demonstrate both practice and exposure to review of the evidence when planning intervention sessions. Finally, in a social climate seeking increased diversity and inclusion, the comments noted by students about critical thinking and cultural considerations within and beyond the classroom experience show great promise for the profession.

While the author asserts that CT skills can never be fully manifested in one course, this pedagogical approach is a first step toward a movement within a given department. Contributing to the emerging body of evidence substantiating the need for explicit instruction (Abrami et al., 2008, 2015) can only continue to support the notion that CT skills and dispositions must be explicitly taught, and assessed, to develop future clinicians. Given the increasingly complex nature of the work of speech-language pathologists and audiologists, there will always be a need for individuals who are thinking critically in all aspects of life, expanding knowledge in critical thinking, continually developing empathy and perspective taking, and contributing to evidence-based practice. Future directions on development of CT skills explicitly within the framework of a course should include more detailed mixed methods design, potentially using a different scale, and with more detailed questions yielding increased qualitative data. Taken together, these preliminary findings may further shed light upon the student process toward CT skill development in future clinicians. In conclusion, critical thinking is considered a necessary life skill not only for clinical practice (the focus here), but also for leading a productive, engaging, fruitful life. Conflicting findings demonstrate the need for increased inquiry using mixed method design, monitoring change over more extended periods of time, and generalization of said changes.

There are four noted limitations to this investigation. First, this was a pilot study to establish feasibility and proof of concept; there was no control group asking about attitudes toward critical thinking, which can be fluid. In its current form, the CT initiatives carried out in this singular course (though across three cohorts) are at the mercy of short-term memory and maturation on a 
condensed time line, which may be potential confounds. Second, there was no way to objectively measure observable behavior change in CT, as it is a cognitive and metacognitive skill. To that end, duration of engagement of active learning activities was further not measured. It may be that active engagement in a task for five minutes may have had a differential impact in CT skill development than engagement with a task for 30 minutes. These data were not collected, and therefore cannot be explicitly explored. Third, the active learning activities used in this pilot investigation included paper-based simulations and problem-based learning activities. Perhaps expanding CT activities to include a service-learning component may expand CT skills for graduate students in CSD. Further, while the case-based studies utilized here may be considered paper-based simulations, more detailed and structured simulations, with more advanced resources and technology, may contribute to pedagogical efforts in CT in the profession. Finally, the short timeline of this investigation (15-week span) does not allow for exploration of maturation and extended practice in multiple contexts, leaving generalizability in question. Further support for this explanation is found in the work of Grillo et al. (2015), who offered first year graduate students in CSD a single learning module on CT skills. Grillo and colleagues (2015) found no significant change in student written responses to clinical scenarios. Their findings further support that teaching CT skills is an ongoing and long-term endeavor. Considering these limitations, future investigation of $\mathrm{CT}$ intervention within a pedagogical setting attempting to address these confounds may further illuminate our understanding of best practices in teaching CT skills in Communication Sciences and Disorders. 


\section{Author Disclosure Information}

Financial Disclosure: The author is a fulltime faculty member at (University intentionally not named).

Nonfinancial Disclosure: The author has recently submitted a book chapter to an edited book, with the same editor as this journal. 


\section{References}

Abrami, P. C., Bernard, R. M., Borokhovski, E., Wade, A., Surkes, M. A., Tamim, R., \& Zhang, D. (2008). Instructional interventions affecting critical thinking skills and dispositions: A Stage I meta-analysis. Review of Educational Research, 78, 1102-1134.

Abrami, P. C., Bernard, R. M., Borokhovski, E., Waddington, D. I., Wade, C. A., \& Persson, T. (2015). Strategies for teaching students to think critically: A meta-analysis. Review of Educational Research, 85, 275-314. doi:10.3102/0034654314551063

American Psychiatric Association (2013). Desk Reference to the Diagnostic Criteria From DSM5. American Psychiatric Association.

Burda, A. N., \& Hageman, C. F. (2015). Problem-based learning in speech-language pathology: Format and feedback. Contemporary Issues in Communication Sciences and Disorders, 42, 47-71.

Dudding, C., \& Nottingham, E. E. (2018). A national survey of simulation use in university programs in communication sciences and disorders. American Journal of SpeechLanguage Pathology, 27, 71-81.

Edwards, A. L. (1957). The social desirability variable in personality assessment and research. Dryden Press.

Ennis, R. H. (1987). A taxonomy of critical thinking dispositions and abilities. In J. Baron \& R. Sternberg (Eds.), Teaching thinking skills: Theory and practice (pp. 9-26). W. H. Freeman.

Facione, P. A. (1990). Critical thinking: A statement of expert consensus for purposes of educational assessment and instruction. Research findings and recommendations. American Philosophical Association. 
Finn, P. (2011). Critical thinking: Knowledge and skills for evidence-based practice. Language, Speech, and Hearing Services in the Schools, 42, 69-72.

Finn, P., Brunage, S. B., \& DiLollo, A. (2016). Preparing our future helping professionals to become critical thinkers: A tutorial. Perspective on Issues in Higher Education, 1(2),4368.

Grillo, E. U., Koenig, M. A., Gunter, C. D., \& Kim, S. (2015). Teaching CSD graduate students to think critically, apply evidence, and write professionally. Communication Disorders Quarterly, 36(4), 241-251.

Jansen, L. J. (2015). The benefits of simulation-based education. Perspective on Issues in Higher Education, 18, 32-42.

Krathwohl, D. R. (2002). A revision of Bloom's taxonomy: An overview. Theory into Practice, 41, 212-218. doi:10.1207/s15430421tip4104_2. ISSN 0040-5841

Meltzoff, J., \& Cooper, H. (2018). Critical thinking about research: Psychology and related fields (2nd ed.). American Psychological Association. https://doi.org/10.1037/0000052000

Mpofu, E. (2007). Service-learning effects on the academic learning of rehabilitation services students. Michigan Journal of Community Service Learning, 14(1), 46-52.

Morris, R. J., Gorham-Rowan, M. M., Robinson, J.H., \& Scholz, K. (2018). Assessing and teaching critical thinking in communication science and disorders. Teaching and Learning in Communication Sciences \& Disorders: Vol. 2 (1), 1-26. doi.org/10.30707/TLCSD2.1Morris

Paul, R., \& Elder, L. (2009). Miniature guide to critical thinking concepts and tools. Foundation for Critical Thinking Press. 
Peters, K. A. (2011). Including service learning in the undergraduate communication sciences and disorders curriculum: Benefits, challenges, and strategies for success. American Journal of Audiology, 20, S181-S196.

Sosu, E. M. (2013). The development and psychometric validation of a critical thinking disposition scale. Thinking Skills and Creativity, 9, 107-119. http://dx.doi.org/10.1016/j.tsc.2012.09.002

Visconti, C. F. (2010). Problem-based learning: Teaching skills for evidence-based practice. Perspectives on Issues in Higher Education, 13, 27-31. doi:10.1044/ihe13.1.27

Yu, D., Zhang, Y., Xu, Y., Wu, J., \& Wang, C. (2013). Improvement in critical thinking dispositions of undergraduate nursing students through problem-based learning: A crossover experimental study. Journal of Nursing Education, 52, 574-581.

Zraick, R. (2013). Review of the use of standardized patients in speech-language pathology clinical education. International Journal of Therapy and Rehabilitation, 19(2), 112118. https://doi.org/10.12968/ijtr.2012.19.2.112 
Appendix

(Survey Scale adapted from Sosu, 2013).

Instructions: For each of the statements below, please indicate to what extent the statement is characteristic of you. If the statement is extremely uncharacteristic of you (not at all like you), Please circle the number underneath each question. If the statement is extremely characteristic of you (very much like you), please circle a " 5 " under the question. Of course, a statement may be neither extremely uncharacteristic nor extremely characteristic of you; if so, please use the number in the middle of the scale that describes the best fit. Please keep the following scale in mind as you rate each of the statements below.

$1=$ extremely uncharacteristic

$2=$ somewhat uncharacteristic

$3=$ uncertain

$4=$ somewhat characteristic

$5=$ extremely characteristic

1. I would prefer complex to simple problems.

2. I like to have the responsibility of handling a situation that requires a lot of thinking.

3. Thinking is not my idea of fun

4. I would rather do something that requires little thought than something that is sure to challenge my thinking abilities.

5. I try to anticipate and avoid situations where there is a likely chance I will have to think in depth about something.

6. I find satisfaction in deliberating hard and for long hours.

7. I only think as hard as I have to.

8. I prefer to think about small, daily projects to long-term ones.

9. I like tasks that require little thought once I've learned them.

10. The idea of relying on thought to make my way to the top appeals to me.

11. I really enjoy a task that involves coming up with new solutions to problems.

12. Learning new ways to think doesn't excite me very much.

13. I prefer my life to be filled with puzzles that I must solve.

14. The notion of thinking abstractly is appealing to me.

15. I would prefer a task that is intellectual, difficult, and important to one that is somewhat important but does not require much thought.

16. I feel relief rather than satisfaction after completing a task that required a lot of mental effort.

17. It's enough for me that something gets the job done; I don't care how or why it works.

18. I usually end up deliberating about issues even when they do not affect me personally. 